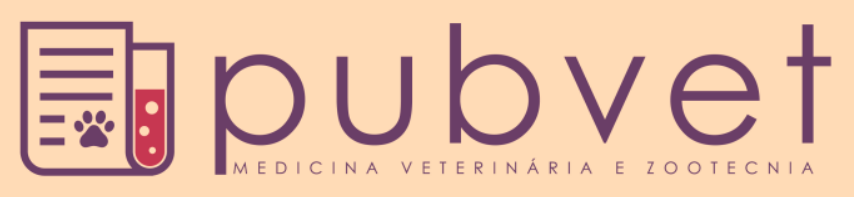

https://doi.org/10.31533/pubvet.v12n9a168.1-5

\title{
Osteocondroma em cadela: Relato de caso
}

\author{
Beatryz Fonseca da Silva*1ø, Arline Oliveira ${ }^{2}$, Ricardo Ferraz Brito Passos $^{3 \oplus}$ \\ ${ }^{I}$ Médica Veterinária da Universidade Federal do Tocantins, Clínica Veterinária Universitária. Araguaína-TO. beatryzfonseca@uft.edu.br \\ ${ }^{2}$ Médica Veterinária, Goiânia-Goiás, lliny_@hotmail.com \\ ${ }^{3}$ Médico Veterinário, Anápolis - Goiás, ricpassos@gmail.com \\ *Autor para correspondência
}

\begin{abstract}
RESUMO. Neoplasias ósseas primárias benignas, como o osteocondroma, possuem poucos relatos em cães e gatos. Normalmente acomete animais jovens, pois estes possuem o centro de ossificação endocondral ativos, os sinais clínicos podem se manifestar devido à compressão e deformação de estruturas adjacentes como, claudicação, dor, paralisia e fraqueza progressiva. Neste trabalho, relata-se um caso de osteocondromatose em uma cadela, da raça Rottweiler, nove anos de idade, com histórico de claudicação do membro pélvico direito e hiporexia. O diagnóstico foi baseado em exames macroscópicos e histopatológico y como forma de tratamento optou se pelo procedimento cirúrgico de desarticulação coxofemoral direita.
\end{abstract}

Palavras chave: claudicação, dor, tumores ósseos

\section{Osteochondroma in a female dog: case report}

ABSTRACT. Benign primary bone neoplasms, such as osteochondroma, have few reports in dogs and cats. Usually affects young animals, as these have the active endochondral ossification center, clinical signs may manifest due to compression and deformation of adjacent structures such as lameness, pain, paralysis and progressive weakness. In this work, we report a case of osteochondromatosys in a 9-year-old Rottweile female dog with a history of limb claudication of the right pelvic limb and hyporexia. The diagnosis was based on macroscopic and histopathological exams, as a form of treatment chosen by the coxofemoral disarticulation right.

Keywords: lameness, pain, bone neoplasm

\section{Osteocondroma en la perra: Reporte de un caso}

RESUMEN. Las neoplasias óseas primarias benignas, como el osteocondroma, poseen pocos relatos en perros y gatos. En la mayoría de los casos, afecta animales jóvenes, pues estos poseen el centro de osificación endocondral activos, los signos clínicos se pueden manifestar debido a la compresión y formación de estructura adyacente como, claudicación, dolor, parálisis y debilidad progresiva. En este trabajo, se reporta un caso de osteocondromatosis en una perra, de la raza Rottweile, nueve años de edad con historial de claudicación del miembro pélvico derecho e hiporexia. El diagnóstico se basó en exámenes macroscópicos e histopatológicos y como forma de tratamiento optó por la desarticulación coxofemoral derecha.

Palabras clave: cojera, dolor, tumor óseo

\section{Introdução}

O Osteocondroma é um tumor ósseo benigno, que pode acometer animais jovens seja na sua forma simples ou múltiplo. A forma múltipla tem sido chamada de exostoses cartilaginosas múltiplas. Sua origem provém de perturbações 
anulares ou semianulares do anel pericondrial de fises metafisárias de ossos longos e contribuem para um encurtamento do membro assim como um padrão de deformidade angular simétrica bilateral, como o que ocorre em jovens afetados pela Osteocondromatose (Kleiner \& Silva, 2003).

O local mais comum de envolvimento é a região metafisária dos ossos longos do membros, como o fêmur distal, úmero superior, tíbia superior e fíbula, no entanto, os osteocondromas também ocorrem em ossos chatos, em particular o ílio e a escápula. Os sinais clínicos associados a membros e vértebras manifestam-se por, claudicação, dor, fraqueza progressiva ou paralisia. Osteocondromas localizado nas vias aéreas superiores como traqueia, apresentam desconforto respiratório (Goldschmidt \& Thrall, 2010).

Os Osteocondromas apresentam características que permitem diagnóstico radiográfico, quando se evidencia osso cortical e esponjoso que apresenta continuidade com o osso adjacente, facilmente identificável nos exames radiográficos convencionais e ratificados com métodos de imagem com capacidade tridimensional, como a tomografia computadorizada e a ressonância magnética (Gomes et al., 2007). A ressecção está indicada quando houver compressão de nervos, artérias, tendões ou quando a exostose estiver interferindo com o crescimento da extremidade, levando as alterações funcionais ou mecânicas (Kleiner \& Silva, 2003).

O objetivo do trabalho é descrever um caso de Osteocondromatose em uma cadela de nove anos idade que apresentou como manifestação clínica claudicação e dor cujo tratamento indicado foi à amputação por desarticulação coxofemoral direito.

\section{Material e Métodos}

Foi atendida no Hospital Veterinário São Francisco de Assis da Faculdade Anhanguera de Anápolis uma cadela de nove anos de idade, da raça Rottweiler, com histórico de mastectomia unilateral direita recente, dificuldade em apoiar o membro pélvico direito, sem histórico de trauma, emagrecimento e hiporexia. Ao exame clínico observou aumento de volume na região distal do fêmur direito com sensibilidade dolorosa e os demais parâmetros não apresentaram alterações. Solicitou se exame radiográfico do fêmur direito, tórax (Figura 1), hemograma, pesquisa de hemoparasito e perfil bioquímico. Os exames hematológicos como o perfil bioquímico não evidenciaram alterações.

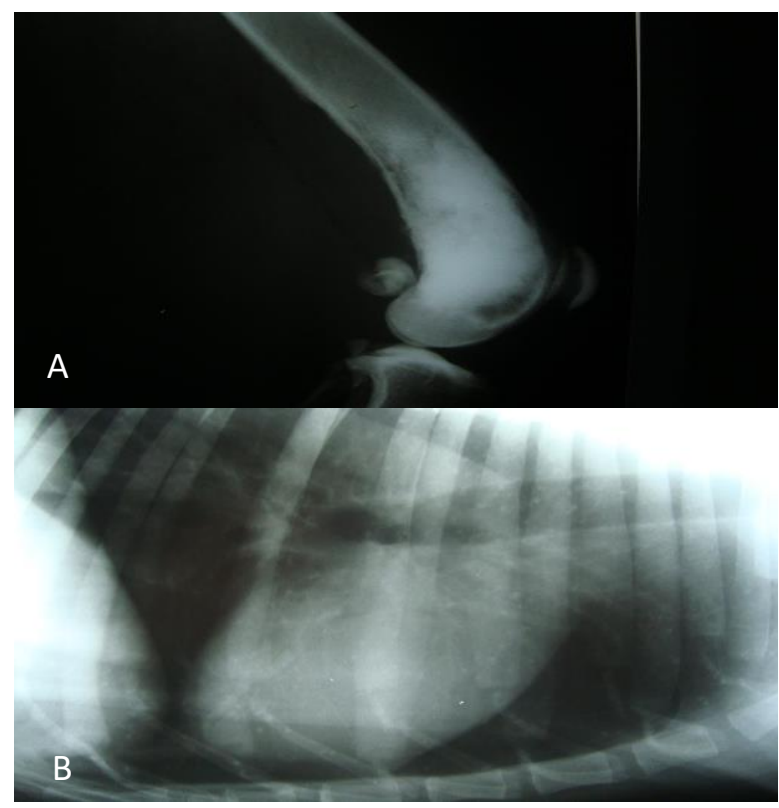

Figura 1. (A) Projeção médio- cranial do Joelho do Membro Pélvico direito (B) Projeção Latero-Lateral esquerda do tórax.

O exame radiográfico (Figura 1) evidenciou a presença de massa intraóssea na região metafisária distal do fêmur e do tórax inúmero nódulos calcificados. Suspeitou se de osteossarcoma e metástase pulmonar.

Indicou-se procedimento cirúrgico de amputação por desarticulação coxofemoral seguida de avaliação histopatológica da massa óssea do fêmur direito (Figura 2).

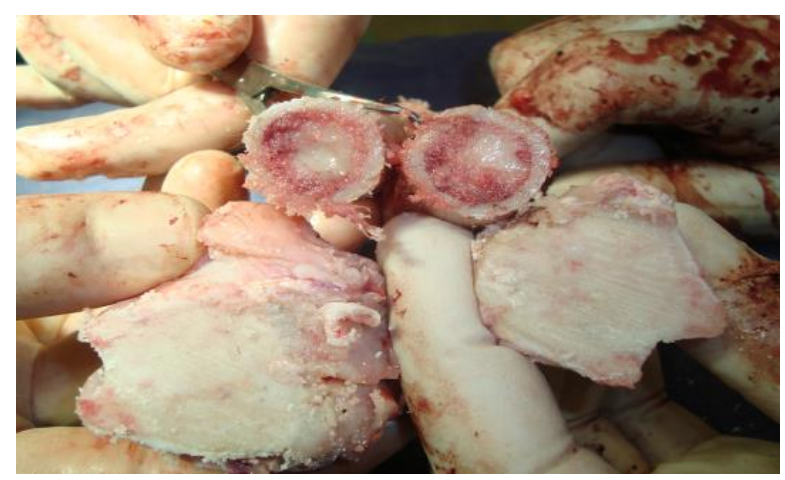

Figura 2. Fragmentos ósseos de fêmur direito.

A avaliação histopatológica evidenciou tecidos moles que exibem áreas de proliferação de tecido ósseo e cartilaginoso, onde apresentou um quadro histológico compatível com Osteocondroma.

Após 15 dias do procedimento cirúrgico, o paciente retornou ao HOVET, para uma avaliação do estado geral e retirada das suturas, que apresentarem alguns focos de deiscência, e 
segundo a proprietária, já mostrou sinais de melhora, alimentando-se bem e com mais disposição.

\section{Discussão}

Neoplasia óssea pode originar-se primariamente no tecido ósseo, como resultado de metástases de neoplasias epiteliais, ou mesenquimais, ou ser oriunda da disseminação de um tumor de tecido mole local. Os tumores ósseos primários são os mais prevalentes (Slatter, 2007), e incluem: osteossarcoma, condrossarcoma, fibrossarcoma, hemangiossarcoma, tumor de células gigantes, lipossarcoma periosteal, osteomas, osteoma multilobular, condroma multilobular, Osteocondroma e condroma (Fossum, 2005).

De acordo com a definição da OMS de 2002, é uma cartilagem neoplasica óssea benigna tampada na superfície externa ossos pré-formados pela ossificação endocondral (Khurana et al., 2002).

Sua incidência em animais é considerada é rara (Withrow et al., 2013) em humanos a neoplasia representa cerca de 50\% dos tumores ósseos primários tratados cirurgicamente e sua prevalência é maior em homens sendo 1,5: $1 \mathrm{em}$ relação a mulheres (Hameetman et al., 2004)

A origem é controversa, existe a hipótese de stress em áreas tendinosas, resultando em hipercrescimento ósseo (Dantas et al., 2008), como também da modificação na direção de crescimento da placa fisária, com protrusão lateral de porções dessa placa, causando o desenvolvimento de proeminências ósseas, excêntricas e cobertas de cartilagem (Garcia, 2004).

Podem surgir durante o período de crescimento e raramente são responsáveis por complicações vasculares (Tornquist et al., 2007). A paciente apresentava se com nove anos de idade, fêmea da raça Rottweiller, apesar da Literatura escassa os trabalhos relatados inferem que a maior prevalência é em machos, jovens das raças Terries, Poodle Toy, Dog Alemão e Boxer (Dias et al., 2017) e Gambardella et al. (1975), observou que casos que ocorrem após a maturidade óssea podem ser considerados atípicos.

Uma etiologia semelhante pode explicar casos de Osteocondromas secundários induzidos por trauma, manipulação cirúrgica ou irradiação (Gomes et al., 2007). O Osteocondroma pode estar localizado nas metáfises dos ossos longos, geralmente em regiões extra-articulares (Alves et al., 1999). Podem se apresentar como lesões sésseis (base maior que altura) ou pediculadas (base menor que altura), os quais se originam na metáfise e se orientam em direção oposta à articulação adjacente, devido às forças de tração de tendões e ligamentos (Gomes et al., 2007). Pei et al. (2010) relata que seres humanos $70 \%$ está relacionado a mutações dos genes EXT1 e EXT2.

Alguns Osteocondromas provêm de perturbações anulares ou semianulares do pericôndrio de fises metafisárias de ossos longos e contribuem para um encurtamento do membro assim como um padrão de deformidade angular simétrica bilateral, como o que ocorre em crianças afetadas pela Osteocondromatose (Kleiner \& Silva, 2003).

Os sinais clínicos associados são devidos à compressão e deformação de estruturas adjacentes. Lesões nos membros produzem claudicação, dor, fraqueza progressiva ou paralisia e nas vias aéreas superiores causa desconforto respiratório (Goldschmidt \& Thrall, 2002).

Estes apresentam características que permitem diagnóstico radiográfico, quando se evidencia osso cortical e esponjoso que apresenta continuidade com o osso adjacente, identificável nos exames radiográficos convencionais e ratificados com Tomografia Computadorizada e Ressonância Magnética Além disso, esses últimos métodos são importantes na avaliação de lesões em ossos chatos, com anatomia complexa como a escápula e/ou em vértebras e arcos costais (Gomes et al., 2007).

Ao exame macroscópico, os Osteocondromas se apresentam sob a forma de massas de base ampla e séssil, de coloração branca ou brancoazulada, refletindo a capa da cartilagem que recobre os múltiplos nódulos com uma fina camada de córtex e espaço medular. Microscopicamente, observa-se que a neoplasia é constituída de crescimento bifásico, representado por uma margem apical da cartilagem hialina e uma base de tecido ósseo esponjoso intercalado por canais medulares (Vieira et al., 2009). Observa-se que a avaliação histopatológica foi fundamental para a conclusão do diagnóstico.

A presença de um tumor solitário não é uma indicação absoluta para sua ressecção cirúrgica. A exerese está indicada quando houver compressão de nervos, artérias, tendões ou quando a exostose estiver interferindo com $\mathrm{o}$ crescimento da 
extremidade. Durante a cirurgia, a exostose com sua capa cartilagínea e o pericôndrio devem ser removidos como um bloco, na tentativa de evitar a recorrência do processo (Garcia, 2004). Neoplasias ósseas benignas, como o condroma, osteoma, fibroma ossificante e por possuir uma lenta progressão e dependendo da acessibilidade do tumor, uma ampla excisão cirúrgica na maioria das vezes se mostra curativa (Andrade, 2008).

Normalmente os Osteocondromas são indolores, a paciente apresentava relutância ao andar, apoiar e dor a palpação na extremidade distal do fêmur direito, optou se pelo procedimento cirúrgico da desarticulação coxofemoral direito por causa da dor que demonstrava (Andersson, 2009), a faixa etária, o histórico de neoplasia mamária e a suspeita de malignidadade. Gambardella et al. (1975) destaca que excisão precoce diminui o rico de malignidade. Em Humanos cerca de $1 \%$ com lesões solitárias evoluem para neoplasia maligna (Hameetman et al., 2004). Outras alterações benignas podem adquirir características malignas após manipulação cirúrgica (ex: cistos ósseos), sendo importante à realização de uma excisão cirúrgica completa, quando possível, para eliminar ou prorrogar a recorrência dos sinais clínicos (Kleiner \& Silva, 2003).

\section{Conclusão}

Neoplasias primárias benignas ósseas em pequenos animais possuem pouco relatos na literatura e normalmente são do tipo múltiplas e acometem animais mais jovens que são tratados paliativamente, a cadela deste relato tinha nove anos de idade e apresentou um tumor do tipo simples cujo tratamento realizado foi o procedimento de amputação coxofemoral, após a exérese houve evolução clínica favorável com boa adaptação dos membros, alerta e o retorno a normorexia. O Osteocondorma é incomum em cães que atingiram a maturidade óssea o que demonstra a importância do exame histopatológico ou a biopsia em animais com suspeita de alterações ósseas.

\section{Referências}

Alves, M. P. T., Dias, L. H. \& Campos, M. M. 1999. Osteocondroma da extremidade proximal da ulna: relato de caso. Revista Brasileira de Ortopedia, 34(7).
Andersson, A. C. 2009. Multiple cartilagenous exostoses in the dog. The European Journal of Companion Animal Practice, 19, 61-66.

Andrade, S. A. F. 2008. Tumores ósseos em cães. Revista UNILUS, 5(9), 5-12.

Dantas, J. F. C., Conte, N. N., Silva, L. M. C., Kluppel, L. E. \& Beiro, A. C. 2008. Osteocondroma: revisão da literatura. Revista Faculdade Odontologia Universidade Federal Bahia, 27, 55-61.

Dias, E. A. N. L., Cavalcanti, G. A. O. \& Pereira, L. F. 2017. Exostose cartilaginosa múltipla: Relato de caso. Pubvet, 7 (12), 1227-1232.

Fossum, T. W. 2005. Cirurgia de pequenos animais ( $2^{\mathrm{a}}$ ed.). Roca, São Paulo, BR.

Gambardella, P. C., Osborne, C. A. \& Stevens, J. B. 1975. Multiple cartilaginous exostoses in the dog. Journal of the American Veterinary Medical Association, 166, 761-768.

Garcia, R. J. 2004. Tumores ósseos: uma abordagem ortopédica ao estudo dos tumores ósseos. Escola Paulista de Medicina. Moreira J.R, São Paulo, BR.

Gomes, F. S. E., Lewin, F., Mariotti, G. C., Cruz, R. O., Baptista, P. P. R., Yonamine, E. S., ... \& Yamaguchi, C. K. 2007. Osteocondromas: avaliação por imagem das complicações. Revista Imagem, 29, 53-59.

Goldschmidt, M. H \& Thrall, D. E. 2002. Tumores benignos do osso do cão. In: Meuten D.J. (Ed.), Tumors in Domestic Animals. 4th ed. Iowa State Press, Ames.

Hameetman, L., Bovée, J. V. M. G., Taminiau, A. H. M., Kroon, H. M. \& Hogendoorn, P. C. W. 2004. Multiple osteochondromas: clinicopathological and genetic spectrum and suggestions for clinical management. Hereditary Cancer in Clinical Practice, 2, 161- 173.

Kleiner, J. A. \& Silva, E. G. 2003 Tumores ósseos em pequenos animais. Revista Científica de Medicina Veterinária MedVep,1(3).

Khurana, J., Abdul-Karim, F. \& Bovée, J. V. M. G. 2002. Osteochondroma. In: Fletcher, C. D. M., Unni, K. K. \& Mertens, F. (eds.) World Health Organization classification of tumours Pathology and genetics of tumours of soft tissue and bone. IARC Press, Lyon, França.

Pei, Y., Wang, Y., Huang, W., Hu, B., Huang, D., Zhou, Y. \& Su, P. 2010. Novel mutations of EXT1 and EXT2 genes among families and sporadic cases with multiple exostoses. 
Genetic Testing and Molecular Biomarkers, $14,865-872$.

Slatter, D. 2007. Manual de cirurgia de pequenos animais (3a ed., p. 2460-2469). Manole, Barueri, BR.

Vieira, A. L. S., Xavier, M. N., Costa, É. A., Lavalle, G. E. \& Santos, R. de L. 2009 Osteocondromatose em um Dachshund: relato de caso. Revista Clínica Veterinária,79, 38-42.

Tornquist, F. A., Leopardo, C. C., Segala, T. C. \& Hamid, A. j. A. A. 2007. Vascular complication of osteochondroma: case report. Journal Vascular Brasileiro, 6 (1), 92-96.
Withrow, S. J., Page, R. \& Vail, D. M. 2013. Withrow and MacEwen's Small Animal Clinical Oncology-E-Book. Elsevier Health Sciences, St. Louis, US.

Recebido: 18 Julho. 2018

Aprovado: 14 Agosto. 2018

Publicado: 18 Setembro 2018

Licenciamento: Este artigo é publicado na modalidade Acesso Aberto sob a licença Creative Commons Atribuição 4.0 (CC-BY 4.0), a qual permite uso irrestrito, distribuição, reprodução em qualquer meio, desde que o autor e a fonte sejam devidamente creditados. 